\title{
High-value materials from incineration residues of burnable garbage
}

\section{-Production of silica with high specific surface area from "molten slag" and direct transformation of silica to basic raw material for silicon chemical industry-}

\author{
Norihisa FuKaYA ${ }^{1 *}$, Sho KATAOKa ${ }^{2}$ and Jun-Chul $\mathrm{CHOI}^{1}$
}

[Translation from Synthesiology, Vol.11, No.3, p.128-136 (2018)]

\begin{abstract}
We developed a technology for producing silica with high specific surface area from molten slag discharged by a garbage disposal plant The obtained silica has purity and specific surface area comparable to commercially available synthetic silica. Therefore, this silica can be used in various applications, such as in adsorbents, rubber additives, and coating agents. Previous use of silica recycled from molten slag was limited to aggregate for concrete or asphalt. This research result means that silica recycled from molten slag can now be used as a functional material. We also report on "direct synthesis technology of functional chemicals using silica" as the starting point for this research, the research scenario, and future prospects.
\end{abstract}

Keywords : Molten slag, silica, mesoporous silica, silicon

\section{Introduction}

\subsection{Outline of this research}

The authors developed technology to manufacture silica with high specific surface area using molten slag that is generated from incineration plants for municipal garbage, in association with Mitsui E\&S Engineering, Co., Ltd. (hereinafter, Mitsui E\&S; was called Mitsui Shipbuilding \& Engineering Co., Ltd. at the time this research was started; the company name was changed in April 2018). Silica with high specific surface area obtained using the jointly developed technology allows molten slag produced in venous industries (municipal garbage incineration plants) to be utilized as functional materials for arterial industries (chemical and materials industries). In this paper, we report the background for this development, the outline of the technology to advance the use of molten slag, and the future prospects.

\subsection{Scenario of this research}

Figure 1 shows the overall scenario for matching technological potential (the seeds) and industrial demands (the needs) based on social issues that spurred this research, the road to discovery of technology, and the future prospects. The technological development for manufacturing functional materials from molten slag was conducted by the National Institute of Advanced Industrial Science and Technology (hereinafter, AIST) that was tackling the social issue "Achievement of energy savings in silica chemical products manufacturing" in the project of the New Energy and Industrial Technology Development Organization (NEDO).
AIST took on the challenges of finding solutions to topics such as "achievement of high efficiency in garbage treatment by local governments (improvement of profitability)" and "further use of distributed energy facilities" as new research topics. When the project is organized into Fig. 1, one realizes that when research results progress to the next stage, collaboration with human resources with different specialties is important, and it can be seen that the key point is to transmit the significance of the research results in a comprehensive manner when building such collaborative relationships and to have the results be recognized widely throughout society in the process of "result dissemination." Since the field of specialties were totally different among the specialists who had the knowledge of plant operation for waste disposal plants at Mitsui E\&S, the researchers working on chemical reaction and molecular design at the Interdisciplinary Research Center for Catalytic Chemistry, AIST, and the researchers studying chemical engineering or surface chemistry at the Research Institute for Chemical Process Technology, AIST, there was no opportunity for these people to directly exchange opinions in usual activities such as at academic meetings or at paper presentations. As R\&D specialties become more diversified, it is becoming difficult to scan other fields or even science and technology in general. Therefore, events such as the Techno Bridge Fair in which AIST's technological potential is introduced to people of industry are important, so they can get an overview of the research conducted at AIST and to transmit the results widely and systemically. Looking back, it can be said that the breakthrough point of this research was the matchmaking

1. Interdisciplinary Research Center for Catalytic Chemistry, AIST Tsukuba Central 5, 1-1-1 Higashi, Tsukuba 305-8565, Japan * E-mail: n.fukaya@aist.go.jp, 2. Research Institute for Chemical Process Technology, AIST Tsukuba Central 5, 1-1-1 Higashi, Tsukuba 305-8565, Japan

Original manuscript received March 16, 2018, Revisions received July 15, 2018, Accepted July 18, 2018 
between the "seeds" and "needs" of the specialists from totally different fields, and the fact that they were able to start joint research to tackle new topics.

Moreover, in this research, announcement was made in the form of a joint press release for the results of joint research by Mitsui E\&S and AIST. As a result, during the first half of the research period, joint research was started to tackle new topics, and in the latter half, we received several inquiries from companies that "wanted to use the silica made from molten slag," and this led to user acquisition for sample distribution work. In the next chapter, details of the activities will be described along the scenario.

\section{Background of development}

\subsection{Current situation of municipal garbage disposal}

Ever since the Great East Japan Earthquake, importance is increasing for the usage and popularization of autonomous distributed energy. ${ }^{[1]}$ Municipal garbage disposal plants are capable of utilizing thermal energy generated when disposing garbage, and are drawing attention as distributed energy recovery facilities that are constructed in every local government unit throughout Japan. On the other hand, incineration ashes are produced after burning garbage at these disposal plants, and most of them are buried in landfill sites. However, in some disposal plants, to reduce the volume of ashes, they are melted at high temperature, cooled in water, and recovered as vitrified solids called "molten slag."
According to the statistics for FY 2015, there are 1,141 municipal garbage disposal plants in Japan. There are several disposal methods, and there are 220 plants with melting facilities to produce molten slag. ${ }^{[2]}$ Although this is $20 \%$ of the total number of municipal garbage disposal plants, power generation capacity is $3,645 \mathrm{GWh}$, and this is $45 \%$ of the total $8,175 \mathrm{GWh}$ generated by municipal garbage disposal plants. This is important value of power generation plants.

\subsection{Characteristic of molten slag}

The main components of molten slag derived from garbage are $\mathrm{SiO}_{2}, \mathrm{CaO}$, and $\mathrm{Al}_{2} \mathrm{O}_{3}$. Although the composition ratio may fluctuate depending on region or season, the total of these three components is about $70 \mathrm{wt} \%$ of the composition, and $\mathrm{SiO}_{2}$ is about $40-50 \%$. The production volume of molten slag at municipal garbage disposal plants that treat general waste in Japan reaches about 800,000 ton/year (FY 2015) (Fig. 2). In 2006, two JIS standards (JIS A5031 and JIS A5032; one for concrete aggregate and the other for roads) were established to define the safety of molten slag and to promote its effective use. The items for quality control include physical properties (density, water absorption, abrasion loss, etc.), chemical properties (composition, etc.), and safety tests (elution amount and content of hazardous materials). The current use of molten slag is mostly for construction material. Most uses are for infrastructure construction including about $34 \%$ as road aggregate and about $17 \%$ as concrete aggregate (Fig. 3 ). ${ }^{[2]}$

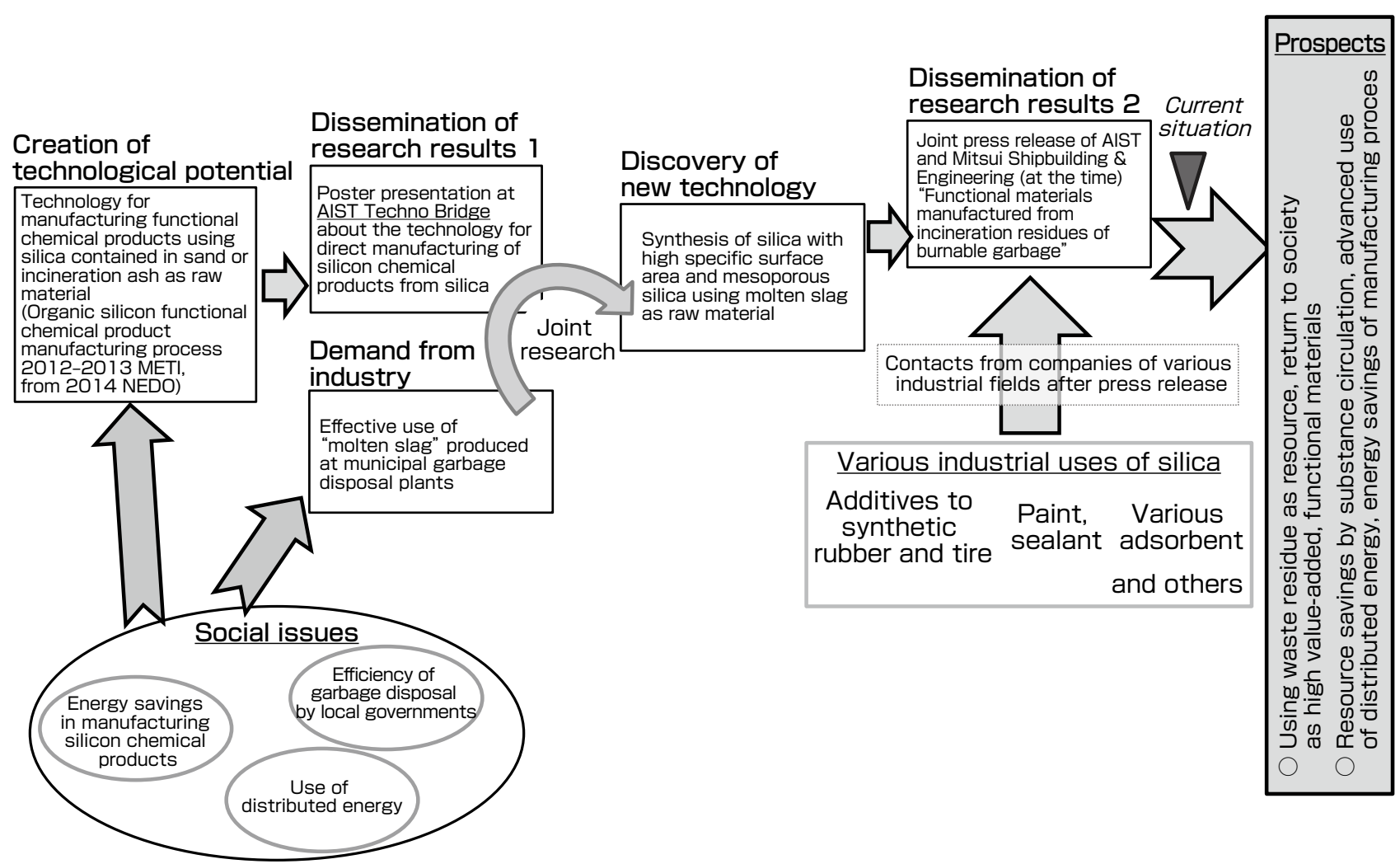

Fig. 1 Scenario of this research and future prospects 


\subsection{For additional effective use of molten slag}

Currently, there are high demands for civil engineering construction materials such as aforementioned road and concrete aggregates due to infrastructure construction for the 2020 Olympics and Paralympics as well as for recovery from earthquake disasters. However, there is concern that the amount of molten slag produced by garbage disposal plants may become excessive against the demand after the Olympics. Therefore, there is demand for technological development to create high added-value materials from molten slag and to enable effective use in wide-ranging fields. Mitsui E\&S is an engineering company that conducts business with local governments to construct, operate, and maintain garbage disposal plants. The company has strong interest in developing methodology for effective use of molten slag, and was looking for technological potential at universities and public institutions to solve the problem.

On the other hand, the Interdisciplinary Research Center for Catalytic Chemistry, AIST has been engaging in R\&D for various organosilicon materials including silicone that was used in a wide-range of industrial fields in the NEDO Project "Development of the manufacturing process technology for organosilicon functional chemical products" (FY 2012-2021). The authors gave a poster presentation of the research results of the above NEDO Project at the AIST Techno Bridge held on October 22-23, 2015. R\&D personnel of Mitsui E\&S visited the exhibition and became interested in the content of "Direct synthesis of silicon key chemical products using silica as raw material." They contacted the authors later, and the possibility for the effective use of molten slag and incineration ash that were produced from energy facilities was discussed, and joint research was started. In the following subchapter, we explain the outline of the technological potential created through the results of the NEDO Project that was the preliminary step to joint research.

\subsection{Outline of the NEDO Project "Development of the manufacturing process technology for organic silicon functional chemical products"}

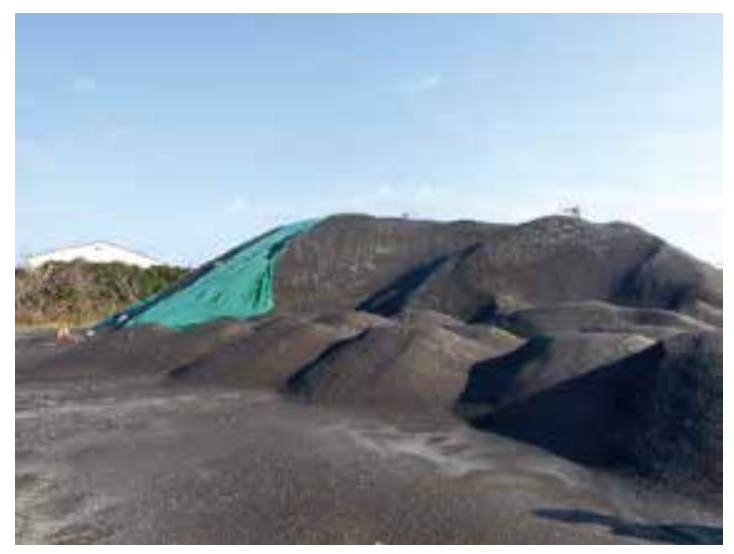

Fig. 2 Storage yard of molten slag
Silicon is the second most abundant element after oxygen, among the components that comprise the earth surface. In nature, it exists in the form of silica that is the main component of rock and sand. There are many materials containing silicon around us, and it is used in various forms. The organic silicon chemicals represented by silicone and silane coupling agents have excellent physical properties from the viewpoints of heat resistance, weather resistance, chemical resistance, insulation property, and others. They are functional materials used widely in industrial fields such as of automobiles, aerospace, construction, electronics, medicine, cosmetics, and others. A compound called tetraalkoxysilane (e.g. tetraethoxysilane is known by the abbreviation TEOS) is widely used as raw material of inorganic silicon material and is a key substance essential for making protective films for electronic devices, as well as optical materials such as functional ceramics, glass, and synthetic quartz.

Chemical products containing silicon that are used in various materials must be reduced to metallic silicon by making the starting material, natural quartzite, react with carbon at high temperature. This process requires a large amount of electric energy, and at the same time, produces a large amount of carbon dioxide $\left(\mathrm{CO}_{2}\right)$. This is the main factor that makes chemical materials containing silicon relatively expensive products, even though silicon is an element that exists abundantly on this planet. There is expectation for the development of technology to directly synthesize siliconcontaining chemical products from silica that is reasonably priced and exists abundantly in Japan (Fig. 4).

The authors aimed to develop a new manufacturing method for organic silicon chemical products that did not take the route of metal silicon, and worked on the development of technology to synthesize tetraalkoxysilane directly from silica, and succeeded in achieving a highly efficient reaction process. The characteristic of this technology is that a

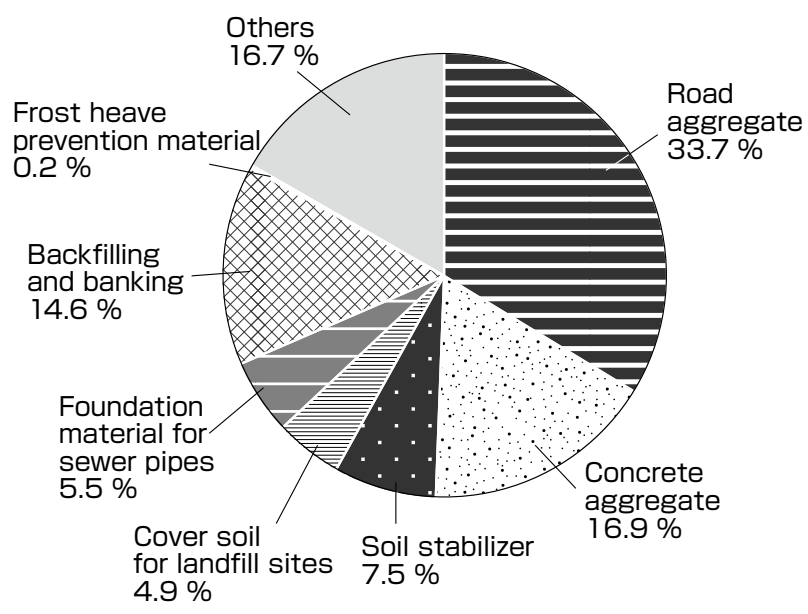

Fig. 3 Current situation of use of molten slag (from garbage and sewage sludge $)^{[2]}$ 
Table 1. Results of direct synthesis of tetraethoxysilane from various natural materials

\begin{tabular}{|c|c|c|}
\hline $\begin{array}{l}\text { Raw material } \\
\text { containing silica }\end{array}$ & $\begin{array}{l}\text { Purity of silica in } \\
\text { raw materials }\end{array}$ & Tetraethoxysilane yield \\
\hline Sand ${ }^{a}$ & $90 \%$ & $51 \%$ \\
\hline Incineration ash from chaff & $93 \%$ & $78 \%$ \\
\hline Incineration ash from straw & $84 \%$ & $72 \%$ \\
\hline Industrial by-products ${ }^{b}$ & $95 \%$ or more & $72 \%$ \\
\hline
\end{tabular}

a: Obtained by crushing siliceous shale from Natsudomari Penninsula, Aomori Prefecture (provided by Asaka Riken Co., Ltd.) b: Silica produced as by-product of synthetic quartz manufacturing (provided by CoorsTek K.K.)

process was designed to remove water continuously during the reaction by installing a water removal unit in the reaction system. This enables conversion to useful chemical products through direct reaction, even for $\mathrm{SiO}_{2}$ that is a substance for which chemical conversion is normally difficult since it is an extremely stable oxide. Since the molecular sieve, or the inorganic desiccant used here, is solid, it can be easily recovered after the reaction and used repeatedly after heating and evacuation. This is advantageous for reducing manufacturing costs (Fig. 5). ${ }^{[3]-[6]}$

As a starting material containing silica, the following materials were used: sand (obtained by crushing siliceous shale from Natsudomari Penninsula, Aomori Prefecture), incineration ash (remains of burning chaff and straw), and an industrial by-product (silica produced as a by-product

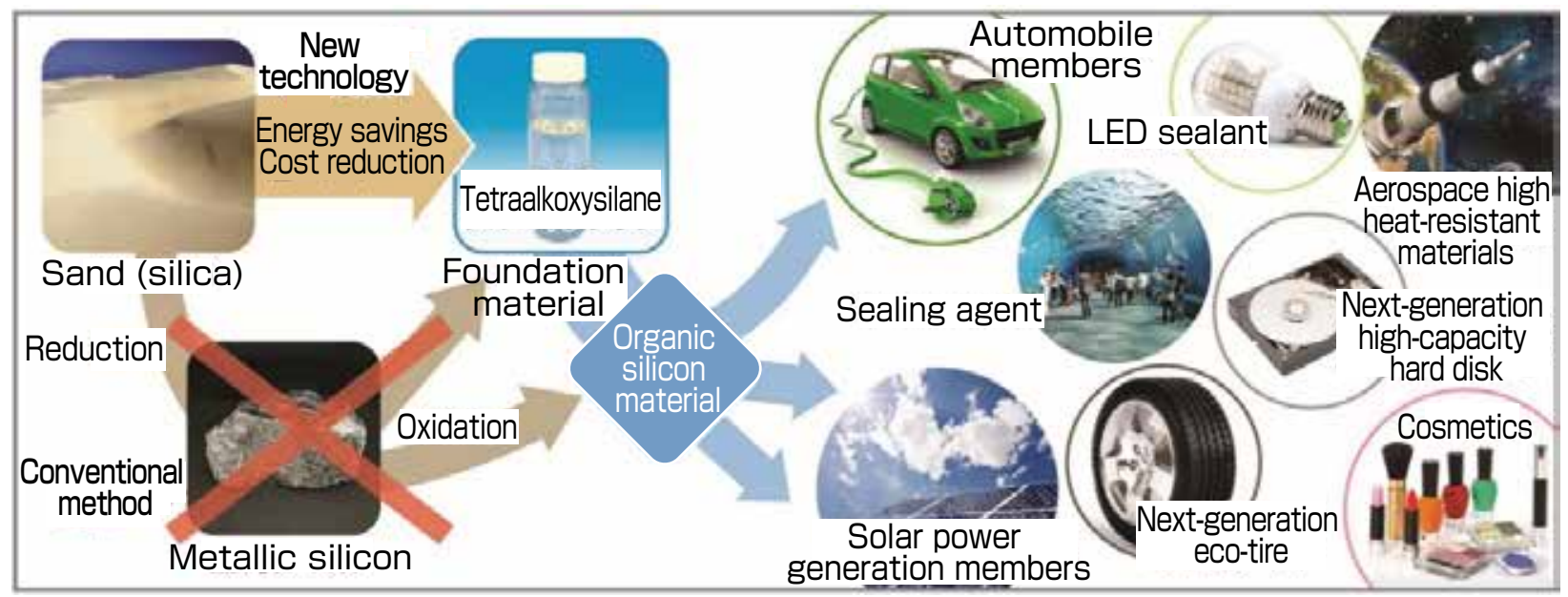

Fig. 4 Manufacture of organic silicon material from sand $\left(\mathrm{SiO}_{2}\right)$, and various product groups that contain organic silicon materials

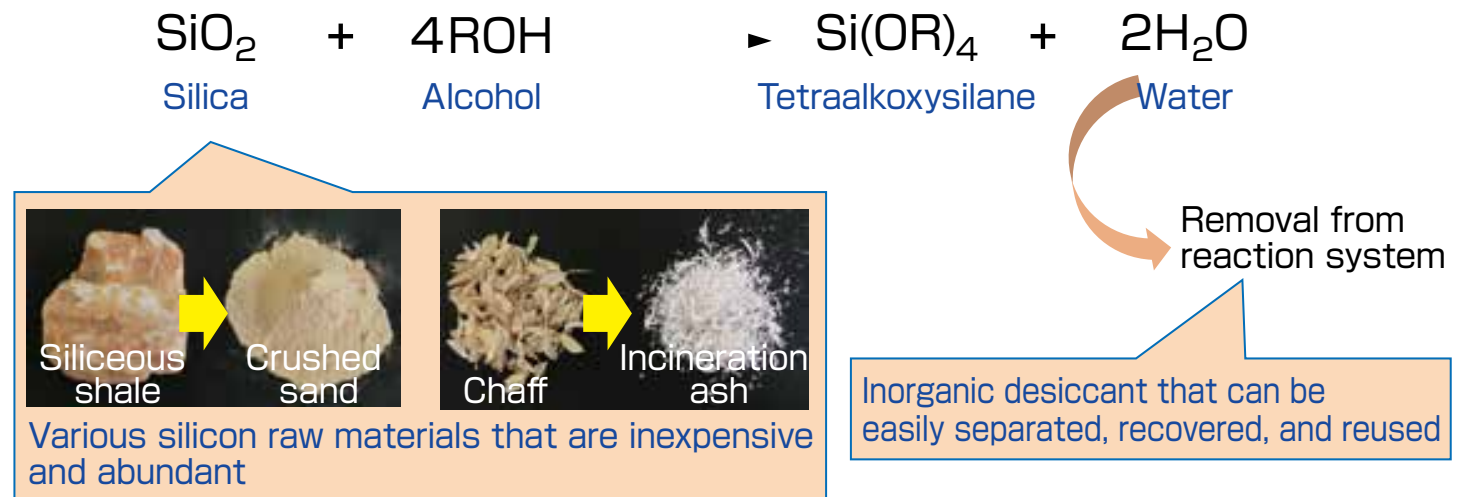

Fig. 5 Direct synthesis of organic silicon material using silica as raw material 
in manufacturing synthetic quartz). Ethanol and catalyst potassium hydroxide were added, the mixture was heated along with molecular sieve $3 \mathrm{~A}$ (pore diameter $0.3 \mathrm{~nm}$ ), a type of zeolite, as an inorganic desiccant, and the reaction was conducted for 3 hours. Table 1 shows the results of the reaction. TEOS was generated at a yield of $51 \%$ based on the silica content. The ashes remaining after burning chaff and straw that are underused resources of agricultural byproducts have relatively high silica purity, and TEOS was obtained at a yield of $72-78 \%$ when these materials were used for synthesis. The by-products of synthetic quartz manufacturing were recovered and used as the starting material, and TEOS was obtained at a $72 \%$ yield.

The point of difficulty in the development process of this technology was the shift in the idea that allowed molecular sieves to be used in this reaction and the design of the reaction apparatus. The most ideal process to synthesize tetraalkoxysilane from silica and alcohol can be described by an extremely simple chemical reaction equation shown at the top of Fig. 5. However, in practice, this reaction is governed by chemical equilibrium, and since silica is a thermodynamically stable substance, the produced tetraalkoxysilane and water react, and a reverse reaction in which tetraalkoxysilane returns to silica and alcohol occurs much more easily. Thus, it is difficult to obtain tetraalkoxysilane at a good yield. To shift the chemical equilibrium to a desired direction, a dehydration method by which produced water is successively removed from the reaction system is the key. Molecular sieves are desiccants used universally, and normally they are used in direct contact with targets (liquid or gas) to be dehydrated. While having powerful desiccant capabilities, they can also be relatively easily reversed and reused, and high efficiency can be expected if they can be used. However, molecular sieves are crystallized alkaline metal aluminosilicate (alkaline metal salt that is composite of alumina and silica), and a silica unit exists within its structure. Therefore, if molecular sieves are directly introduced to the reaction system whose purpose is to dissolve silica, the structure of the sieve will disintegrate. Therefore, at the beginning of the research, we thought we could not use the sieves for this reaction, and we searched for an organic desiccant that could be directly placed in the reaction system. ${ }^{[4]}$

However, with the progress of the NEDO Project, we became aware of the necessity of developing a simple process that allowed easy separation from the target substance. The desiccant used had to be easily recoverable and reusable, in order to be feasible as the new reaction process was moved up from a laboratory scale to an industrial scale. Therefore, we shifted our way of thinking to how to use a molecular sieve that tended to disintegrate in our reaction condition. We worked on the reaction apparatus, and as shown in Fig. 6 , the vessel for silica and alcohol to react under the presence of a potassium hydroxide catalyst (lower part) and the vessel in which a molecular sieve functioned as a desiccant (top part) were separated. In this reaction apparatus, alcohol and water vaporized in the lower vessel, moved to the upper molecular sieve, and only the water was absorbed and removed. Therefore, the potassium hydroxide catalyst that promoted the breaking of the Si-O-Si bond of silica did not come in contact with the molecular sieve, and the water could be removed successively without the disintegration of the structure.

\section{Manufacturing of high added-value materials from molten slag raw materials}

\subsection{Technology to manufacture silica with high specific surface area from molten slag}

Mitsui E\&S focused on the fact that the research results of the aforementioned NEDO Project involved the "advanced use of silica that was the main component of molten slag" while pointing to the attainment of green sustainable chemistry (GSC). Therefore, the company started joint research with AIST to aim for further effective use of molten slag, particularly for its use in functional materials with new
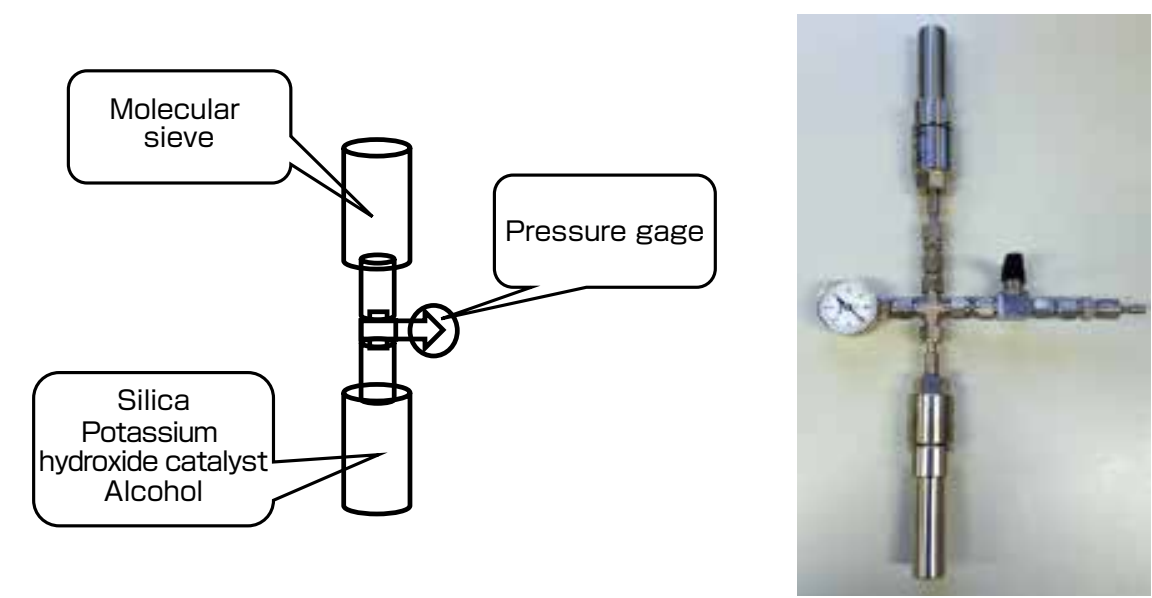

Fig. 6 Schematic diagram of reaction vessel for tetraalkoxylsilane and its photograph $^{[3]}$ 
added value for the "arterial industry," rather than the use in materials such as concrete aggregate for the so-called "venous industry."

It was newly found that by chemically treating the molten slag produced from municipal garbage disposal plants using acidic solutions under certain conditions, the silica component in the molten slag precipitated as white solids. When this white solid was recovered by filtering or other methods, silica with purity of $93-98 \%$ could be easily obtained (Fig. 7).

The estimated mechanism of this reaction is examined. As explained in Subchapter 2.2, the main components of molten slag are $\mathrm{SiO}_{2}, \mathrm{CaO}$, and $\mathrm{Al}_{2} \mathrm{O}_{3}$, and the silicon components are thought to exist as "calcium salt of composite oxide of silicon and aluminum" rather than in a pure silica form. This calcium salt is thought to go through a certain process. After undergoing neutralization by acid, aluminum and calcium become soluble in an acid aqueous solution as ions, and silicon increases molecular weight by a dehydrationcondensation reaction through a catalyst action of acid, after undergoing a low molecular silica condition called silica sol or orthosilicate. Then it precipitates as insoluble white solids as silica undergoes gelling. That is, in this reaction system, acid has two roles: one is to make components other than silica soluble as ions, and the other is to act as a catalyst for silica production by a sol-gel reaction. Since condensation occurs after the sol state in which silica has low molecular weight and is highly dispersed, the silica that is ultimately obtained by gelling is expected to have a high specific surface area.

The results of actual nitrogen gas adsorption measurement showed that the calculated specific surface area was about 600 $\mathrm{m}^{2} / \mathrm{g}$, and this was equivalent or higher than that of synthetic silica material that was commercially available as high specific surface area material. Therefore, it is expected that silica with high specific surface area obtained from molten slag using this technology will have various usages as adsorbents, additives for tires and synthetic rubber, catalyst carriers, in cosmetics, as abrasives, and others, in which synthetic silica is currently used in industry. Also, silica with high specific surface area will have many reaction points that can come in contact with reaction targets such as alcohol or alkaline catalysts. Therefore, when considered as a raw material for chemical reactions, it is expected to be useful in manufacturing tetraalkoxysilane mentioned in Subchapter 2.4.

Currently, silica with high specific surface area used widely in industry includes fumed silica manufactured by a gas phase reaction of silicon tetrachloride in high-temperature hydrogen fire, or precipitated silica (sometimes called white carbon) manufactured by a liquid phase reaction of sodium silicate and sulfuric acid. These manufacturing methods consume much energy for silicon tetrachloride and sodium silicate, and use raw materials manufactured by processes that require a certain degree of cost. On the other hand, the newly developed technology allows the use of residues that are generated irreversibly while disposing burnable garbage produced in our daily lives, and is overwhelmingly inexpensive at about 200 yen/ton even for those with qualities that satisfy the JIS standard. Therefore, compared to the conventional processes, it is expected to contribute to energy savings during silica manufacturing, reduction of carbon dioxide emission, and cost reduction of silica products.

\subsection{Technology to manufacture ordered nano- mesoporous silica from molten slag}

Recently, a porous silica material with ordered and uniform pore sizes of 2-50 nm (mesopores) called mesoporous silica is gaining attention. Mesoporous silica is generally synthesized by using a structure made by self-assembly of surfactants in solution as the mesopore template and forming silica around this template by a sol-gel reaction. Mesoporous silica has an ordered structure and has uniform nanospace within the material, and it is expected as a highly selective reaction field that cannot be realized by existing porous materials. It is a high added-value material for which research is conducted around the world for its application as a high
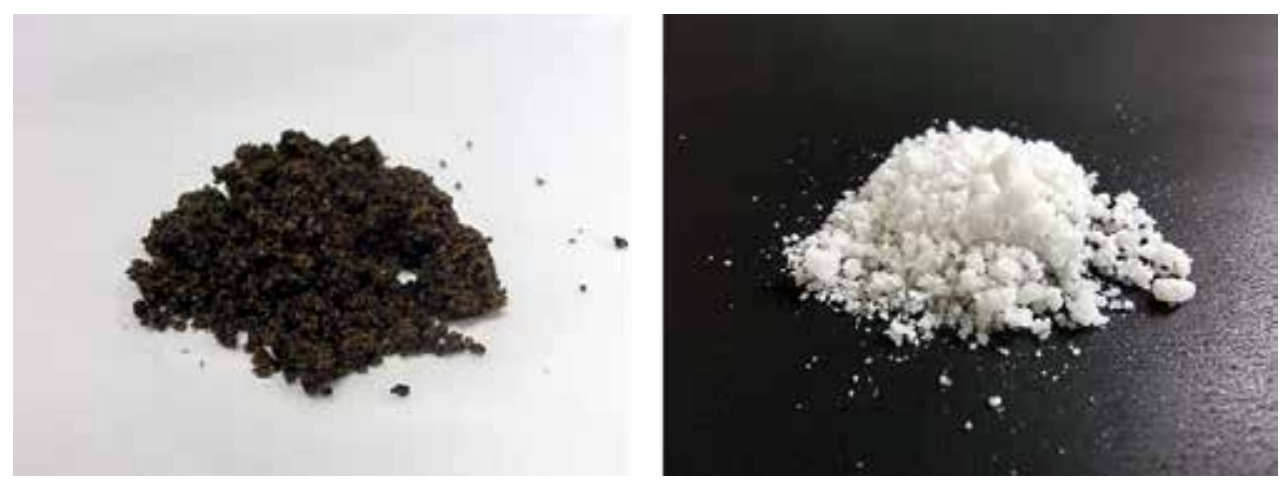

Fig. 7 Raw material molten slag (left) and synthesized silica with high specific surface area (right) 
performance humidity control agent, a drug transfer system, or a catalyst carrier. ${ }^{[7]}$

Silica obtained from molten slag mentioned in the previous subchapter has high specific surface area but does not have a pore structure. Therefore, we engaged in the synthesis of mesoporous silica for the purpose of developing technology to convert molten slag into a higher performance, higher added-value material.

The chemical treatment to obtain silica with high specific surface area shown in the previous subchapter was conducted in a condition in which surfactants that acted as templates to make the pores coexisted. The white solids obtained was fired at $550{ }^{\circ} \mathrm{C}$ to burn away the template, and we were able to obtain mesoporous silica with ordered nano-size pores. The specific surface area of mesoporous silica produced from molten slag was $675 \mathrm{~m}^{2} / \mathrm{g}$ and the average pore size was $9.2 \mathrm{~nm}$. The electron microscope photograph of this mesoporus silica is shown in Fig. 8. The already known mesoporous silica was synthesized from highly pure and relatively expensive silicon raw materials such as colloidal silica and tetraalkoxysilane. On the other hand, molten slag

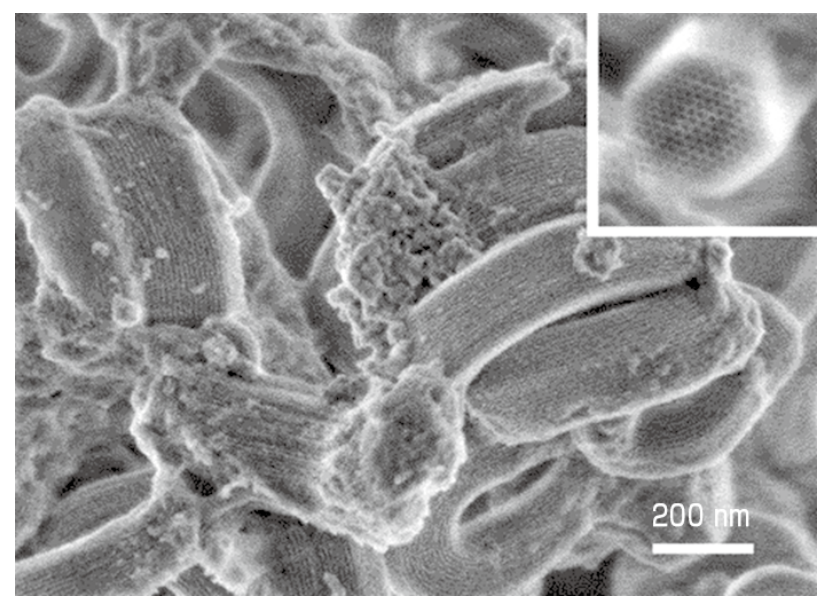

Fig. 8 Electron microscope photograph of mesoporous silica synthesized from molten slag was not pretreated in this technology and contained large amounts of impurities such as calcium and aluminum. We succeeded in synthesizing the material with pores and specific surface areas similar to the conventional mesoporous silica by maneuvering the reaction time and temperature and finding the condition in which self-assembly of the template surfactants progressed.

Both AIST and Mitsui E\&S published press releases of the results of this joint research on July 25, 2017 (Fig. 9) ${ }^{[8][9]} \mathrm{We}$ were contacted by companies of various industries including chemicals, nonferrous metals, ceramics, traders, and others, and we are now preparing for supplying test sample of silica with high specific surface area to users.

\section{Future prospects}

The technology developed in this research can expand the advanced use of molten slag, as it leads to wide-ranging use of silica with high specific surface area that can be made from molten slag whose current use is limited. In the future, we aim to improve the manufacturing process, work on upsizing the manufacturing scale, and try for practical utilization in a few years. Through practical realization of this technology, we hope it leads to such outcomes as added value through effective use of waste residue and resource savings through substance circulation.

\section{Acknowledgement}

The research pertaining to the direct synthesis of organic silicon material using silica as raw material in this paper was conducted as part of the NEDO Project "Development of the manufacturing process technology for organic silicon functional chemical products" (FY 2014 up to the present).

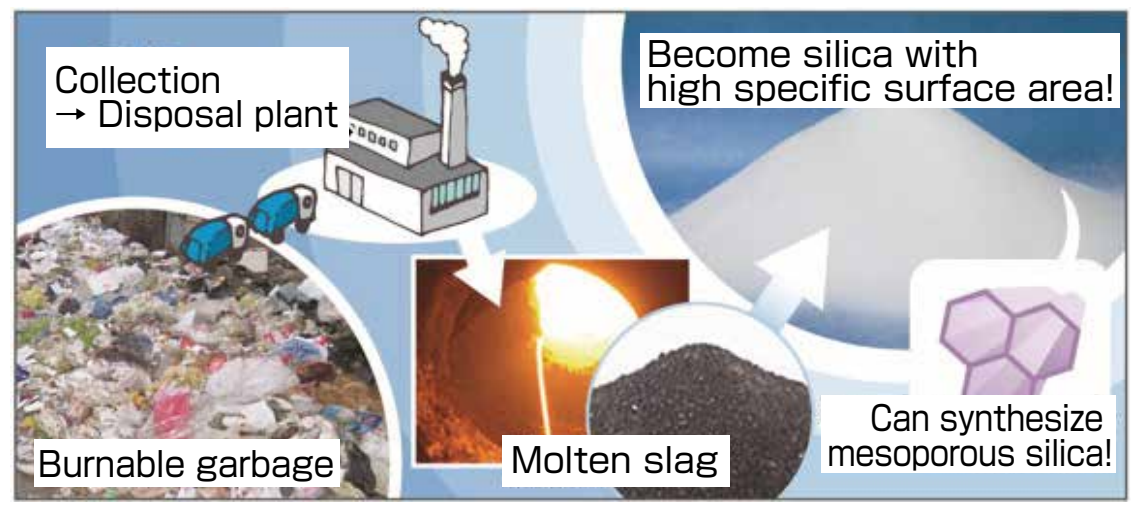

Fig. 9 Conversion of molten slag, incineration residue of burnable garbage, into high added-value material 


\section{References}

[1] Agency for Natural Resources and Energy: Resource Materials for Subcommittee for Long-term Energy Supply \& Demand Outlook, April 2015, Advisory Committee for Energy (in Japanese).

[2] Eco-slag Riyo Fukyu Iinkai: Eco-slag yuko riyo no genjo to data shu 2016 nendo (Current situation of the effective use of eco-slag and data for FY 2016), Japan Society of Industrial Machinery Manufacturers (2016) (in Japanese).

[3] N. Fukaya, S. J. Choi, T. Horikoshi, S. Kataoka, A. Endo, H. Kumai, M. Hasegawa, K. Sato and J. C. Choi: Direct synthesis of tetraalkoxysilanes from silica and alcohols, New Journal of Chemistry, 41 (6), 2224-2226 (2017).

[4] N. Fukaya, S. J. Choi, T. Horikoshi, H. Kumai, M. Hasegawa, H. Yasuda, K. Sato and J. C. Choi: Synthesis of tetramethoxysilane from silica and methanolusing carbon dioxide and an organic dehydrating reagent, Chemistry Letters, 45 (7), 828-30 (2016).

[5] T. T. H. Nguyen, S. Kataoka, N. Fukaya, K. Sato, J. C. Choi and A. Endo: Feasibility study of new synthesis route of tetraethoxysilane from rice hull ash, Computer Aided Chemical Engineering, 40, 703-708 (2017).

[6] T.T.H. Nguyen, N. Fukaya, K. Sato, JC. Choi and S. Kataoka: Technoeconomic and environmental assessment for design and optimization of tetraethyl orthosilicate synthesis process, Industrial \& Engineering Chemistry Research, 57 (6), 2192-2199 (2018).

[7] X. Ma, H. Feng, C. Liang, X. Liu, F. Zeng and Y. Wang: Mesoporous silica as micro/nano-carrier: From passive to active cargo delivery, a mini review, Journal of Materials Science \& Technology, 33 (10), 1067-1074 (2017).

[8] AIST Press Release (2017): Moeru gomi no shokyaku zansa kara kinosei zairyo o seizo (Functional material manufactured from incineration residues of burnable garbage), http://www.aist.go.jp/aist_j/press_release/pr2017/ pr20170725/pr20170725.html, accessed 2018-03-16 (in Japanese).

[9] Mitsui E\&S Holdings Press Release (2017): Moeru gomi no shokyaku zansa kara kinosei zairyo o seizo (Functional material manufactured from incineration residues of burnable garbage), https://www.mes.co.jp/archive-news/ press/2017/20170725.html, accessed 2018-03-16 (in Japanese).

\section{Authors}

\section{Norihisa FuKaYA}

Completed courses at the Graduate School of Chemistry, University of Tsukuba in April 2002; Doctor (Science). Worked at Canon Inc., and then joined AIST in April 2007. After joining AIST, engaged in development of immobilization technology for molecular catalysts and direct manufacturing technology of functional chemical products using sand

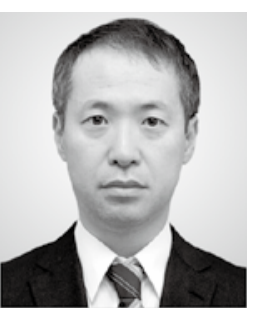
as raw material. Specialties are organic metal chemistry and catalyst chemistry. In this paper, was in charge of the synthesis of silica with high specific surface area from molten slag as well as the general supervision of joint research.

\section{Sho KataOKa}

Completed the courses for Environmental Science and Engineering, College of Engineering, University of WisconsinMadison in May 2003; PhD. Worked as post-doctoral researcher at the Department of Chemistry, Texas A\&M University, and then joined AIST in April 2006. Engaged in the development of porous materials and functional materials of inorganic oxides including silica. Specialties are chemical engineering and surface chemistry. In this paper, was in charge of the synthesis and evaluation of mesoporous silica from molten slag.

\section{Jun-Chul ChоI}

Completed courses at the Interdisciplinary Graduate School of Science and Engineering, Tokyo Institute of Technology in March 1998; Doctor (Science). Worked as Research Fellow, Japan Society for the Promotion of Science, and joined the National Institute of Materials and Chemical Research in April 2000 (reorganized into AIST

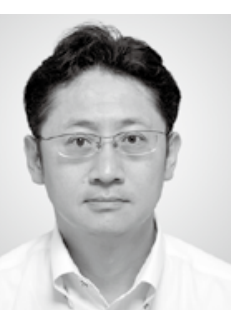
in April 2001). Engaged in development of carbon dioxide conversion technology, immobilized catalyst design and synthesis technology, and conversion technology from sand to useful chemical products. Specialties are organic metal chemistry, organic synthesis chemistry, and catalyst chemistry. In this paper, was in charge of the synthesis experiments of silica with high specific surface area from molten slag.

\section{Discussions with Reviewers}

\section{Overall}

Comment (Naoto Kobayashi, Waseda University)

This paper presents highly significant research result from the perspectives of practical realization through collaboration with industry, as well as technological development and its application, aiming at the effective use of molten slag produced from garbage incineration plants. Also, the concept of conversion from "venous industry" to "arterial industry" is very attractive. On the other hand, the details of the elemental technologies and their mutual relationships were not clear in the first draft, but this became clear in the final draft, and now the whole story is easier to understand. Comment (Keiichi Ikegami, AIST)

This paper describes the development of technology to generate high performance materials that are made from incineration residues that have negative value (requires disposal cost). These materials are valuable in arterial industry, rather than in venous industry. Unlike conventional PET recycling and precious metal recovery that involve sorting and obtaining products with high purity, the innovation here is that smart synthesis is carried out based on the chemical equilibrium theory. As the authors write, it is an excellent example that shows that "when research results progress to the next stage, collaboration with human resources with different specialties is important," and therefore, this paper is appropriate for publication in Synthesiology. 


\section{Collaboration with human resources of different fields} Comment (Keiichi Ikegami)

"When research results progress to the next stage, collaboration with human resources with different specialties is important" is indeed an important point. I think it will increase interest of the readers if you explain more specifically "the collaboration with human resources with different specialties" in each subchapter.

Answer (Norihisa Fukaya)

I added a text in "Subchapter 1.2 Scenario of this research" as follows: "Since the field of specialties were totally different among the specialists who had the knowledge of plant operation for waste disposal plant at Mitsui E\&S, the researchers working on chemical reaction and molecular design at the Interdisciplinary Research Center for Catalytic Chemistry, AIST, and the researchers studying chemical engineering or surface chemistry at the Research Institute for Chemical Process Technology, AIST, there was no opportunity for these people to directly exchange opinions in usual activities such as at academic meetings or at paper presentations. ... Therefore, events such as the Techno Bridge Fair at which AIST's technological potential is introduced to the people of industry are important, so they can get an overview of the research conducted at AIST and to transmit the results widely and systemically. Looking back, it can be said that the breakthrough point of this research was the matchmaking between the 'seeds' and 'needs' of the specialists from totally different fields, and the fact that they were able to start joint research to tackle new topics."

\section{Relationship of the elemental technologies Comment (Naoto Kobayashi)}

The intent of " 2.4 Outline of the NEDO Project 'Development of the manufacturing process technology for organic silicon functional chemical products" is the production of tetraalkoxysilane from silica, and it does not necessarily contribute to the production of "silica with high specific surface area" that was included in the subtitle of the first draft. "3 Manufacturing of high added-value materials from molten slag raw materials" is the only contribution to the subtitle. If you intend to describe the results of both elemental technologies, you should change the subtitle and the research objective, and if the former is contributing greatly to the latter, you should describe their relationship.

Answer (Norihisa Fukaya)

As you indicated, I changed the subtitle so the focus will include the course from molten slag to tetraalkoxysilane (key material of silicon chemical industry). To clarify their relationship, I added a text to the end of Subchapter 3.1 as follows: "Also, silica with high specific surface area will have many reaction points that can come in contact with reaction targets such as alcohol or alkaline catalysts. Therefore, when considered as the raw material for chemical reactions, it is expected to be useful in manufacturing tetraalkoxysilane mentioned in Subchapter 2.4." (Although we do have experimental evidence, only the concept is outlined due to a nondisclosure agreement.)

\section{Details of the strategy}

\section{Comment (Keiichi Ikegami)}

You write, "It was newly found that by chemically treating molten slag produced from municipal garbage disposal plants using acidic solutions under certain conditions, silica components in the molten slag precipitated as white solids." This seems to come up rather abruptly. Perhaps you are not able to disclose the entire process, but can you explain a bit more about how you made this discovery and what strategy you took to achieve this?

\section{Answer (Norihisa Fukaya)}

I added the discussion on the reaction mechanism for this chemical treatment at the beginning of Subchapter 3.1: "The estimated mechanism of this reaction is examined. ... That is, in this reaction system, acid has two roles: one is to make components other than silica soluble as ions, and the other is to act as a catalyst for silica production by a sol-gel reaction. Since condensation occurs after the sol state, in which silica has low molecular weight and is highly dispersed, the silica that is ultimately obtained by gelling is expected to have a high specific surface area."

\section{Advancement of the technology \\ Comment (Keiichi Ikegami)}

You advance the technology further in Subchapter 3.2, but what were the demands and issues in this case? In other words, why did you aim for porosity, not just the high specific surface area? (The improvement of specific surface area is little over 10 $\%$, but can you expect dramatic increase in sales prices if you achieve a porous material?) Also, you write that the chemical treatment is conducted in acidic solution, but did you have any technological barriers in getting the surfactant to work in increased ionic strength?

\section{Answer (Norihisa Fukaya)}

I added the expectation about mesoporous silica materials and the citations for such expectations, to clarify the topics and demands for mesoporous silica. I also added the comment about the necessity of know-how to get the surfactant to function when using molten slag as the raw material. 